\title{
Avaliação de Funções de Governos Estaduais e do Distrito Federal na Percepção dos Contribuintes/Usuários ${ }^{1}$
}

\section{Assessment of Functions of State and Federal District Governments in the Perception of Taxpayers/Users}

\section{Evaluación de Funciones de Gobiernos Estaduales y del Distrito Federal en la Percepción de los Contribuyentes/Usuarios}

\author{
Maurício Corrêa da Silva, Mestre \\ Professor do Departamento de Ciências Contábeis da UFRN \\ Doutorando em Ciências Contábeis (UnB/UFRN/UFPB). \\ Universidade Federal do Rio Grande do Norte - Centro de Ciências \\ Sociais Aplicadas - Departamento de Ciências Contábeis. \\ Endereço: Av. Senador Salgado Filho, S/N - Campus Universitário - \\ Lagoa Nova Natal - RN - Brasil - CEP 59076-000 \\ e-mail: prof.mauriciocsilva@gmail.com
}

Aneide Oliveira Araujo, Dra

Professora do Departamento de Ciências Contábeis da UFRN e do Programa Multiinstitucional e Inter-regional de Pós-Graduação em Ciências Contábeis da UnB/UFRN/UFPB - Doutora em Controladoria e Contabilidade (FEA-USP)

Universidade Federal do Rio Grande do Norte - Centro de Ciências

Sociais Aplicadas - Departamento de Ciências Contábeis.

Endereço: Av. Senador Salgado Filho, S/N - Campus Universitário Lagoa Nova Natal - RN - Brasil - CEP 59076-000 e-mail: aneide@ufrnet.br
Fábia Jaiany Viana de Souza

Contadora do Instituto Federal de Educação, Ciência e Tecnologia do Rio Grande do Norte. Mestra em Ciências Contábeis (UnB/UFPB/UFRN)

Universidade Federal do Rio Grande do Norte - Centro de Ciências Sociais Aplicadas - Departamento de Ciências Contábeis. Endereço: Av. Senador Salgado Filho, S/N - Campus Universitário Lagoa Nova Natal - RN - Brasil - CEP 59076-000. e-mail: fabiajaiany@yahoo.com.br

José Dionísio Gomes da Silva, Dr.

Professor do Departamento de Ciências Contábeis da UFRN e do Programa Multiinstitucional e Inter-regional de Pós-Graduação em Ciências Contábeis da UnB/UFRN/UFPB - Doutor em Controladoria e Contabilidade (FEA-USP).

Universidade Federal do Rio Grande do Norte - Centro de Ciências

Sociais Aplicadas - Departamento de Ciências Contábeis.

Endereço: Av. Senador Salgado Filho, S/N - Campus Universitário Lagoa Nova Natal - RN - Brasil - CEP 59076-000. e-mail: dionisio@ufrnet.br

\section{RESUMO}

Esta pesquisa tem o objetivo de levantar opiniões sobre os graus de satisfação de contribuintes/usuários sobre as funções dos governos estaduais e do distrito federal: legislativa; judiciária; segurança pública; saúde; educação; saneamento; gestão ambiental; desportos e lazer; cultura e administração, através de um questionário em que são atribuídas notas de 1 a 10 . O questionário foi disponibilizado em sítio eletrônico próprio no período de 01 de junho a 12 de julho de 2013. Foi realizada também uma avaliação da eficiência instrumental orçamentária dos 26 Estados e do Distrito Federal do ano de 2012. Os resultados revelaram que o Estado de Minas Gerais, seguido de São Paulo e Mato Grosso do Sul foram os melhores avaliados pelos contribuintes/usuários e Tocantins, Rondônia e Alagoas obtiveram as menores médias nas avaliações das 10 funções de governo. As funções segurança pública e saúde foram avaliadas de forma conjunta com a nota final 3 (18\% e 20\%, respectivamente dos 643 contribuintes/usuários participantes da pesquisa) e educação com a nota 4 (18\%). Em relação a eficiência instrumental orçamentária de 2012, os Estados de Alagoas, Amazonas, Bahia, Ceará e Maranhão foram considerados eficientes, mas em relação à percepção dos contribuintes/usuários, os mesmos ficaram na $27^{\mathrm{a}}, 7^{\mathrm{a}}, 11^{\mathrm{a}}$, $20^{\underline{a}}$ e $22^{\underline{a}}$ posição no ranking da avaliação.

Palavras-chave: Avaliação. Funções de governo. Contribuintes/usuários. Eficiência.

\footnotetext{
${ }^{1}$ Artigo recebido em 07.08.2013. Revisado pelos pares em 27.10.2013 (blind revieww). Ajustado e Aceito para publicação em 05.04.2014. Recomendado para publicação por José Ribamar Marques de Carvalho (Editor Científico). Publicado em 15.08.2014. Organização responsável UACC/CCJS/UFCG.
} 


\section{ABSTRACT}

This research intends to raise opinions concerning the levels of satisfaction of taxpayers/users about the functions of State and the Federal District governments: legislative; judiciary; public security; health; education; sanitation; environmental management; sports and leisure; culture and administration, through a questionnaire in which grades from 1 to 10 are attributed. The questionnaire was made available in a proper electronic site in the period from June $1^{\text {st }}$ and July 12 ${ }^{\text {th, }}$ 2013. An assessment of the budget instrumental efficiency of the 26 States and the Federal District of the year 2012 was conducted as well. The results showed that the State of Minas Gerais, followed by São Paulo and Mato Grosso do Sul, were the most well rated by the taxpayers/users and the States of Tocantins, Rondônia and Alagoas obtained the lowest rates in the assessments of the 10 government functions. The functions "public security" and "health" were evaluated in a joint manner with the final grade of 3 (18\% and 20\%, respectively, of the 643 taxpayers/users who participated in the research) and "education" with grade of $4(18 \%)$. In relation to the budget instrumental efficiency of 2012, the States of Alagoas, Amazonas, Bahia, Ceara and Maranhão were considered efficient, but relative to taxpayers/users' perception, the same States ranked $27^{\text {th }}, 7^{\text {th }}$, $11^{\text {th }}, 20^{\text {th }}$ and $22^{\text {nd }}$ in the assessment ranking.

Keywords: Assessment. Government Functions. Taxpayers/Users. Efficiency.

\section{RESUMEN}

Esta investigación tiene el objetivo de levantar opiniones sobre los grados de satisfacción de contribuyentes/usuarios sobre las funciones de los gobiernos estaduales y del distrito federal: legislativa; judiciaria; seguridad pública; salud; educación; saneamiento; gestión ambiental; deportes y ocio; cultura y administración, a través de un cuestionario en que son atribuidas notas de 1 a 10. El cuestionario fue disponible en sitio electrónico propio en el período de 01 de junio a 12 de julio de 2013. Fue realizada también una evaluación de la eficiencia instrumental presupuestaria de los 26 Estados y del Distrito Federal del año de 2012. Los resultados revelaron que el Estado de Minas Gerais, seguido de São Paulo y Mato Grosso do Sul fueron los mejores evaluados por los contribuyentes/usuarios y Tocantins, Rondônia y Alagoas obtuvieron las menores medias en las evaluaciones de las 10 funciones de gobierno. Las funciones seguridad pública y salud fueron evaluadas de forma conjunta con la nota final 3 (18\% y 20\%, respectivamente de los 643 contribuyentes/usuarios participantes de la investigación) y educación con la nota 4 (18\%). En relación a la eficiencia instrumental presupuestaria de 2012, los Estados de Alagoas, Amazonas, Bahia, Ceará y Maranhão fueron considerados eficientes, pero en relación a la percepción de los contribuyentes/usuarios, los mismos quedaron en la $27^{\underline{a}}, 7^{\underline{a}}, 11^{\underline{a}}, 20^{\underline{a}}$ y $22^{\underline{a}}$ posición en el ranking de la evaluación.

Palabras-clave: Evaluación. Funciones de gobierno. Contribuyentes/usuarios. Eficiencia.

\section{INTRODUÇÃO}

Se a avaliação é uma forma de mensurar o desempenho de programas, é necessário definir medidas para a aferição do resultado obtido. Os critérios mais comuns de avaliação são: eficiência; eficácia; impacto (ou efetividade); sustentabilidade; análise custo-efetividade; satisfação do beneficiário e equidade (COSTA; CASTANHAR, 2003).

Além dos critérios anteriormente citados, Caiden e Caiden (2001) incluem como medidas mais comuns de desempenho: insumos (inputs); carga de trabalho (workload); resultados (outputs); custos (costs) e qualidade e oportunidade dos serviços (service quality and timeliness).

A satisfação do beneficiário avalia a atitude do usuário em relação à qualidade do atendimento que está obtendo do programa. De acordo com Draibe (2001), os indicadores de efetividade tem variações classificadas como efetividade social (capital social; opinião e satisfação dos atores) e efetividade institucional (capacidades institucionais; sustentabilidade e reprodução). 
A efetividade segundo Figueiredo e Figueiredo (1986), pode ser objetiva, subjetiva e/ou substantiva. A efetividade objetiva é o critério de aferição da mudança quantitativa entre o antes e o depois da execução do programa. A efetividade subjetiva torna-se o critério de aferição de mudanças psicológicas, de mudanças nos sistemas de crenças e valores e, notadamente, tem a função de aferir a percepção da população sobre a adequação dos resultados objetivos dos programas aos seus desejos, aspirações de demandas. A efetividade substantiva é o critério de aferição de mudanças qualitativas nas condições sociais de vida da população-alvo.

A formulação de políticas públicas constitui-se no momento em que os governos democráticos traduzem seus propósitos e plataformas eleitorais em programas e ações que produzirão resultados ou mudanças no mundo real (SOUZA, 2006).

As ações governamentais concretizadas em programas, projetos, atividades e operações especiais são registradas e publicadas nos portais de transparência dos governos (federal, estaduais, distrital e municipais) com a agregação das diversas áreas de despesa que competem ao setor público com a denominação de função. A Portaria no 42, de 14 de abril de 1999, do Ministério do Planejamento, Orçamento e Gestão - MPOG - (BRASIL, 1999), relaciona 28 funções de governo, tais como: legislativa; judiciária; administração; segurança pública; assistência social; saúde; educação; cultura; transporte; urbanismo; habitação etc.

Os registros contábeis dos programas de políticas públicas, como por exemplo o Programa - 1060 - Brasil Alfabetizado e Educação de Jovens e Adultos do Ministério da Educação - Lei no 11.653, de 7 abril de 2008 - PPA 2008-2011, são realizados como despesas na função educação.

Diante do acima exposto, esta pesquisa tem o objetivo de levantar opiniões sobre os graus de satisfação de contribuintes/usuários sobre as funções dos governos estaduais e do distrito federal: legislativa; judiciária; segurança pública; saúde; educação; saneamento; gestão ambiental; desportos e lazer; cultura e administração, através de um questionário em que são atribuídas notas de 1 a 10 . Desse modo, a investigação é relevante tanto para o contribuinte/usuário, como forma de ser provocado para manifestar sua opinião; quanto para os governantes, ao conhecerem os resultados e quiçá, poderão mudar suas atitudes.

Para cumprir este objetivo, esta pesquisa está dividida em cinco partes. Após esta introdução, a parte dois trata da fundamentação teórica. A parte seguinte elenca os procedimentos metodológicos utilizados. A quarta parte, os resultados e discussões. A quinta parte, as considerações finais, recomendação e conclusão e finalizando as referências utilizadas.

\section{FUNDAMENTAÇÃO TEÓRICA}

A seguir uma revisão legal e teórica sobre as funções de governo e sobre as avaliações de políticas públicas (ações governamentais). 


\subsection{FUNÇÕES DE GOVERNO}

A Portaria no 42, de 14 de abril de 1999, do MPOG (BRASIL, 1999), relaciona as funções de governo (federal, estadual, distrital e municipal) e as define de acordo com o Quadro 1:

\section{Quadro 1 - Definições de funções de governo}

\begin{tabular}{|l|l|}
\hline \multicolumn{1}{|c|}{ Função } & \multicolumn{1}{|c|}{ Definição } \\
\hline Legislativa & $\begin{array}{l}\text { Elaboração de leis, decretos e resoluções e o controle das contas } \\
\text { dos órgãos de todos os Poderes. }\end{array}$ \\
\hline Judiciária & $\begin{array}{l}\text { As ações desenvolvidas com vista à Defesa do Estado, da Ordem } \\
\text { Econômica e Social, dos Costumes, dos Bens, da Família, da } \\
\text { Pessoa, através do Processo Judiciário e com base nas Fontes de } \\
\text { Direito. }\end{array}$ \\
\hline Segurança Pública & $\begin{array}{l}\text { Representa o conjunto de ações desenvolvidas com vistas à } \\
\text { manutenção da ordem pública, pela vigilância e defesa da } \\
\text { integridade física e dos bens e patrimônio dos cidadãos. }\end{array}$ \\
\hline Saúde & $\begin{array}{l}\text { Representa o conjunto de ações destinadas a atender as } \\
\text { necessidades e promover a melhoria das condições do estado de } \\
\text { saúde da população. }\end{array}$ \\
\hline Educação & $\begin{array}{l}\text { Identifica o conjunto de ações governamentais voltadas à } \\
\text { formação intelectual, moral, social, cívica e profissional do } \\
\text { indivíduo, preparando-o para o exercício consciente da cidadania, } \\
\text { e habilitando-o para uma participação eficaz no processo de } \\
\text { desenvolvimento econômico e social. }\end{array}$ \\
\hline Saneamento & $\begin{array}{l}\text { Ações que visam o abastecimento de água de boa qualidade às } \\
\text { populações, a destinação final dos esgotos domésticos e despejos } \\
\text { industriais e a melhoria das condições sanitárias das } \\
\text { comunidades. }\end{array}$ \\
\hline Cultura & $\begin{array}{l}\text { Ações desenvolvidas para a proteção de recursos naturais, } \\
\text { monitoramento por meio de levantamento sistemático de dados } \\
\text { oceanográficos, meteorológicos, astronômicos e geofísicos, e } \\
\text { controle das condições ambientais. }\end{array}$ \\
\hline Gestão Ambiental & $\begin{array}{l}\text { Representa o atendimento do conjunto de ações que visam o } \\
\text { desenvolvimento dos esportes, da recreação e das aptidões físicas } \\
\text { dos indivíduos. }\end{array}$ \\
\hline $\begin{array}{l}\text { Ações que visam o desenvolvimento, a difusão e a preservação do } \\
\text { conhecimento adquirido e acumulado ao longo da história da } \\
\text { humanidade. }\end{array}$ \\
$\begin{array}{l}\text { Ações desenvolvidas visando harmonizar recursos humanos, } \\
\text { materiais, financeiros, técnicos e institucionais destinados à } \\
\text { administração pública e à elaboração de políticas públicas, bem } \\
\text { como assegurar a eficiência de sua coordenação, } \\
\text { supervisionamento e implementação. }\end{array}$ \\
\hline Fazer
\end{tabular}

Fonte: adaptado da Portaria no ${ }^{2}$, de 14 de abril de 1999 do MPOG. 
Além de definir e elencar as funções de governo (despesas), a referida portaria, estabelece os seguintes conceitos:

- Subfunção representa uma partição da função, visando agregar determinado subconjunto de despesa do setor público;

- Programa é o instrumento de organização da ação governamental que visa à concretização dos objetivos pretendidos, sendo mensurado por indicadores estabelecidos no plano plurianual;

- Projeto é um instrumento de programação utilizado para alcançar o objetivo de um programa, envolvendo um conjunto de operações, restritas no tempo, das quais resulta um produto que concorre para a expansão ou para o aperfeiçoamento da ação de governo;

- Atividade é um instrumento de programação para alcançar o objetivo de um programa, envolvendo um conjunto de operações que se realizam de modo contínuo e permanente, das quais resulta um produto necessário à manutenção da ação do governo; e

- Operações Especiais são despesas que não contribuem para a manutenção das ações de governo, das quais não resulta um produto, e não geram contraprestação direta sob a forma de bens e serviços.

Giacomoni (2000, p. 98) esclarece que: "A finalidade principal da classificação funcional é fornecer as bases para a apresentação de dados e estatísticas sobre os gastos públicos nos principais seguimentos em que atuam as organizações do estado". Desse modo, compreende-se que, a classificação funcional veio para melhorar o entendimento dos cidadãos sobre as ações do Governo, pois apresenta informações gerais sobre suas operações, como se fosse um orçamento resumido.

A classificação por ordem funcional visa conjugar as funções do Governo com os programas a serem desenvolvidos. Esta classificação, parte do entendimento amplo do conceito de função, ou seja, de uma classificação que procure identificar os objetivos da intervenção governamental no desenvolvimento social e econômico da comunidade (KOHAMA, 2009).

O Estado para cumprir suas funções (legislativa, judiciária, segurança pública, saúde, educação, cultura, saneamento etc.) necessita realizar os desembolsos financeiros (pagamentos) decorrentes da contratação de serviços de terceiros, de fornecimento de bens etc. Os desembolsos correspondem às despesas governamentais.

As despesas governamentais são classificadas nas categorias econômicas: despesas correntes (destinadas para o pagamento de juros e encargos de dívida; despesas de pessoal e outras despesas correntes) e despesas de capital (despesas de investimentos; inversões financeiras e refinanciamento e pagamento de dívidas: empréstimos e financiamentos).

Os recursos necessários para a administração pública cumprir seus objetivos são denominados de receitas. Silva (2009) esclarece que denomina-se receita pública 
o conjunto dos recursos ou rendas que o Estado dispõe entregues através da contribuição da coletividade para fazer face as suas necessidades.

As receitas são classificadas nas categorias econômicas: receitas correntes (recursos necessários para a manutenção da máquina administrativa - despesas correntes) e receitas de capital (investimentos em obras públicas, instalações e o pagamento de dívidas - despesas de capital).

\subsection{AVALIAÇÕES DE POLÍTICAS PÚBLICAS}

De acordo com Ala-Harja e Helgason (2000), não há consenso quanto ao que seja avaliação, haja vista que o conceito admite múltiplas definições e variedades de disciplinas (economia, formulação de políticas e procedimentos administrativos, sociologia etc.) e clientes abrangidos no universo das avaliações.

A avaliação é, por definição, pesquisa social aplicada: busca um equilíbrio entre o rigor metodológico e técnico de uma investigação social e o pragmatismo e flexibilidade necessários a um instrumento de apoio ao processo decisório (COTTA, 2001). Ainda de acordo com a autora, avaliar significa formar um juízo de valor com base na comparação entre uma situação empírica e uma situação ideal.

Cohen e Franco (2012) definem avaliação como uma atividade que tem como objetivo maximizar a eficácia dos programas na obtenção de seus fins e a eficiência na alocação de recursos para a consecução dos mesmos.

Já para Ramos e Schabbach (2012), avaliação é um instrumento importante para a melhoria da eficiência do gasto público, da qualidade da gestão, do controle social sobre a efetividade da ação do Estado, esse último instrumentalizado pela divulgação de resultados das ações de governo.

$\mathrm{Na}$ análise e avaliação de políticas implementadas por um governo, fatores de diferentes natureza e determinação são importantes. Especialmente quando se focaliza as políticas sociais (usualmente entendidas como as de educação, saúde, previdência, habitação, saneamento etc.), os fatores envolvidos para a aferição de seu "sucesso" ou "fracasso" são complexos, variados, e exigem grande esforço de análise. Estes diferentes aspectos devem estar sempre referidos a um contorno de Estado no interior do qual eles se movimentam (HÖFLING, 2001).

Segundo Cohen e Franco (2012), nem todas as avaliações dos projetos sociais são iguais e assim pode-se estabelecer diferenças entre eles em função do tempo de realização, de quem as realiza, da escala dos projetos e dos destinatários, conforme demonstrando no Quadro 2:

\section{Quadro 2 - Classificação e tipos de avaliação de projetos sociais}

\begin{tabular}{|l|l|}
\hline \multicolumn{1}{|c|}{ Classificação/Critérios } & \multicolumn{1}{c|}{ Tipo } \\
\hline $\begin{array}{l}\text { Em função do momento em que se realiza e os } \\
\text { objetivos que persegue }\end{array}$ & $\begin{array}{l}\text { - Avaliação ex-ante; } \\
\text { - Avaliação ex-post (avaliação de processos e } \\
\text { de impactos). }\end{array}$ \\
\hline
\end{tabular}




\begin{tabular}{|l|l|}
\hline Em função de quem realiza & - Avaliação externa; \\
& - Avaliação interna; \\
& - Avaliação mista; \\
& - Avaliação participativa. \\
\hline Em função da escala dos projetos & - Avaliação de grandes projetos; \\
& - Avaliação de projetos pequenos. \\
\hline Em função dos destinatários da avaliação & - Avaliação para dirigentes superiores; \\
& - Avaliação para os administradores; \\
& - Avaliação para os técnicos. \\
\hline
\end{tabular}

Fonte: adaptado de Cohen e Franco (2012).

Observa-se que no Quadro 2 são sintetizados critérios e tipos de avaliação de projetos sociais que atendem as avaliações que podem ser aplicadas em diversas áreas de conhecimento.

Um dos critérios utilizados na avaliação das políticas públicas e que é determinado pela Constituição Brasileira de 1988 (BRASIL, 1988) é a eficiência (princípio constitucional). Figueiredo e Figueiredo (1986) argumentam que o conceito de eficiência na esfera pública é bidimensional: eficiência instrumental e eficiência política. Os autores definem a eficiência instrumental como a relação estrita entre custos econômicos e benefícios que são, em geral, tangíveis e divisíveis e a eficiência política como a relação entre os "custos" sociais ou políticos, e os benefícios deles derivados.

As avaliações de eficiência no setor público tem aumentado com a utilização do modelo matemático denominado de Análise Envoltória de Dados (DEA). As avaliações de eficiência deste modelo comparam se uma ou mais entidades foram eficientes em relação às demais.

Neste sentido, pode-se observar as avaliações de eficiência nas áreas de saúde e educação realizadas por Faria, Jannuzzi e Silva (2008); programa bolsa família realizadas por Pedroso, Calmo e Bandeira (2009), bem como na área de saneamento realizada por Sato (2011).

O conceito de eficiência é relativo: compara o que foi produzido (produtos outputs - indicadores etc.), dados os recursos utilizados (insumos - inputs - etc.), com o que poderia ter sido produzido com os mesmos recursos.

Modesto (2000) define o princípio da eficiência no setor público como: a exigência jurídica, imposta à administração pública e àqueles que lhe fazem as vezes ou simplesmente recebem recursos públicos vinculados de subvenção ou fomento, de atuação idônea, econômica e satisfatória na realização das finalidades públicas que lhes forem confiadas por lei ou por ato ou contrato de direito público.

\section{PROCEDIMENTOS METODOLÓGICOS}

A presente investigação foi desenvolvida sob a forma de pesquisa empírica para traduzir os graus de satisfação de contribuintes/usuários sobre a execução de 10 das 28 funções de governo dos Estados Brasileiros e o Distrito Federal. 
Foi elaborado um questionário (enviado por e-mail e disponibilizado no link constante do Quadro 3) para professores e alunos das diversas Instituições de Ensino e contatos diversos, bem como foi solicitado que os mesmos enviassem para seus contatos. Os respondentes informaram o Estado/DF que residem e atribuíram as notas de 1 a 10 nas funções de governo, conforme escala e instruções contidas no Quadro 3. O sítio eletrônico da pesquisa foi disponibilizado no período de 01 de junho de 2013 a 12 de julho de 2013.

\section{Quadro 3 - Pesquisa de Avaliação de funções de Governos Estaduais e do Distrito Federal na percepção dos contribuintes/usuários}

\begin{tabular}{|c|c|c|c|c|c|c|c|c|c|c|c|}
\hline \multicolumn{12}{|c|}{ Graus de satisfação - escala } \\
\hline Péssimo & 1 & 2 & 3 & 4 & 5 & 6 & 7 & 8 & 9 & 10 & Excelente \\
\hline \multicolumn{4}{|c|}{ Funções avaliadas } & \multicolumn{8}{|c|}{ Instruções complementares } \\
\hline \multicolumn{4}{|c|}{1 Função Legislativa } & \multicolumn{8}{|c|}{$\begin{array}{l}\text { Poder Legislativo Estadual - Assembleia Legislativa/Distrital - } \\
\text { Deputados Estaduais e Distrital }\end{array}$} \\
\hline \multicolumn{4}{|c|}{2 Função Judiciária } & \multicolumn{8}{|c|}{ Poder Judiciário Estadual e Distrital - Justiça Estadual } \\
\hline \multicolumn{4}{|c|}{3 Função Segurança Pública } & \multicolumn{8}{|c|}{ Poder Executivo Estadual/Distrital - Policiamento etc. } \\
\hline \multicolumn{4}{|c|}{4 Função Saúde } & \multicolumn{8}{|c|}{ Poder Executivo Estadual/Distrital - Hospitais Estaduais } \\
\hline \multicolumn{4}{|c|}{5 Função Educação } & \multicolumn{8}{|c|}{ Poder Executivo Estadual/Distrital - Escolas Estaduais } \\
\hline \multicolumn{4}{|c|}{6 Função Saneamento } & \multicolumn{8}{|c|}{ Poder Executivo Estadual/Distrital - Tratamento de água e esgoto } \\
\hline \multicolumn{4}{|c|}{7 Função Gestão Ambiental } & \multicolumn{8}{|c|}{ Poder Executivo Estadual/Distrital - Controle Ambiental } \\
\hline \multicolumn{4}{|c|}{8 Função Desportos e Lazer } & \multicolumn{8}{|c|}{ Poder Executivo Estadual/Distrital - Esportes e Lazer } \\
\hline \multicolumn{4}{|c|}{9 Função Cultura } & \multicolumn{8}{|c|}{$\begin{array}{l}\text { Poder Executivo Estadual/Distrital - Patrimônio Histórico e } \\
\text { Artístico }\end{array}$} \\
\hline \multicolumn{4}{|c|}{10 Função Administração } & \multicolumn{8}{|c|}{$\begin{array}{l}\text { Poder Executivo Estadual/Distrital - Orçamento - Receitas } \\
\text { Estaduais - ICMS, IPVA etc. }\end{array}$} \\
\hline Link: & \multicolumn{11}{|c|}{ https://docs.google.com/forms/d/1Wy71/2OHIi8Qtn4cYfI4KH-PzeIDV3x2XmDHfG13aC4/viewform } \\
\hline
\end{tabular}

Fonte: elaboração própria.

Os resultados das avaliações dos contribuintes/usuários em todos os 26 Estados e o DF foram tabulados, conforme Tabela 1 e para convalidar a pesquisa, foi realizada uma comparação do ranking das notas atribuídas pelos mesmos com um ranking da aplicação dos recursos (escores) por parte dos governantes realizado com a utilização da Análise Envoltória de Dados (Tabela 3).

A Análise Envoltória de Dados ou Teoria da Fronteira, DEA (sigla inglesa para Data Envelopment Analysis ou Frontier Analysis) baseia-se em modelos matemáticos não paramétricos para avaliar o desempenho de organizações e atividades sem exigir relações funcionais entre os insumos e os produtos (FERREIRA; GOMES, 2009, p. 19).

As variáveis (inputs e outputs) necessárias para o cálculo da eficiência instrumental orçamentária dos Estados e do Distrito Federal, com a utilização do software SIAD v.3.0 - Sistema Integrado de Apoio à Decisão v.3.0. (MEZA et al., 2011) estão no Quadro 4. 
Quadro 4 - Definição de variáveis para a realização da Análise Envoltória de Dados.

\begin{tabular}{|l|l|l|}
\hline DMU & \multicolumn{2}{|l|}{ Estados e o Distrito Federal } \\
\hline Insumos & Input1 & Receita Total per capita \\
\hline \multirow{5}{*}{ Produtos } & Output1 & Legislativa / Despesa total \\
\cline { 2 - 3 } & Output2 & Judiciária / Despesa total \\
\cline { 2 - 3 } & Output3 & Segurança Pública / Despesa total \\
\cline { 2 - 3 } & Output4 & Saúde / Despesa total \\
\cline { 2 - 3 } & Output5 & Educação / Despesa total \\
\cline { 2 - 3 } & Output6 & Saneamento / Despesa total \\
\cline { 2 - 3 } & Output7 & Gestão Ambiental / Despesa total \\
\cline { 2 - 3 } & Output8 & Desportos e Lazer / Despesa total \\
\cline { 2 - 3 } & Output9 & Cultura / Despesa total \\
\cline { 2 - 3 } & Output10 & Administração / Despesa total \\
\hline
\end{tabular}

Fonte: elaboração própria.

As DMUs (Unidades de Tomada de Decisão - Decision Making Units) são os 26 Estados e o Distrito Federal. A inclusão do Distrito Federal se justifica pelo orçamento e por utilizar recursos como Estado e Município, mas tal situação não o caracteriza para ser excluído das tomadas de decisão com porte de Estado.

O input 1 (insumo) é a receita total per capita do ano de 2012 (receitas correntes e de capital). A questão "per capita" para o insumo (input1) procura relativar estatisticamente as diferenças nos portes dos orçamentos avaliados e nas diferenças estruturais dos próprios Estados e o Distrito Federal.

Os outputs 1 a 10 (produtos) representam indicadores de avaliação de execução orçamentária das funções de governo escolhidas divididas pela despesa total (despesas correntes e de capital executadas no ano considerado).

Convém registrar que estas variáveis são utilizadas para avaliar a política orçamentária executada. Já houve a escolha política pela sua aplicação. Representam a qualidade do gasto público. Desse modo, as questões subjacentes ao processo orçamentário como planejamento, contingenciamento etc. não são avaliadas (podem ser objetos de outros estudos).

Foi usado no DEA, o modelo CCR orientado a outputs, pois maximiza as saídas (indicadores de outputs 1 a 10), mantendo inalteradas as entradas (input1), ou seja, os recursos arrecadados pelos Estados e o Distrito Federal são avaliados por seus resultados nos indicadores escolhidos (o que deveria o governante ter feito com o que foi arrecadado).

A investigação social foi fundamentada com a realização de referencial teórico necessário para argumentar e dialogar com o propósito em questão.

O universo (população) da pesquisa é do tipo intencional, compreendendo todos os 26 Estados Brasileiros e o Distrito Federal. Os dados sobre a execução orçamentária do ano de 2012 foram extraídos do sítio eletrônico da Secretaria do Tesouro Nacional (STN). 


\section{RESULTADOS E DISCUSSÕES}

Esta seção contém a descrição, resultados e discussões sobre os dados coletados. Inicialmente, apresentam-se as respostas do total de 643 contribuintes/usuários de todos os Estados e o Distrito Federal (Tabela 1) e de forma conjunta (Tabela 2). Em seguida, expõem-se os resultados dos escores de avaliação da eficiência instrumental da política orçamentária do ano de 2012 (Tabela 3).

\section{Tabela 1 - Ranking das médias aritméticas das notas atribuídas pelos contribuintes/usuários}

\begin{tabular}{|c|c|c|c|c|c|}
\hline Estados/DF & Funções & $\begin{array}{c}\text { Avaliações } \\
\text { (média) }\end{array}$ & Funções & $\begin{array}{l}\text { Avaliações } \\
\text { (média) }\end{array}$ & $\begin{array}{c}\text { Ranking } \\
\text { (média geral) }\end{array}$ \\
\hline & Legislativa & 4,81818 & Saneamento & 6,22727 & \\
\hline 1. Minas & Judiciária & 5,27273 & Gestão Ambiental & 5,22727 & \\
\hline \multirow[t]{4}{*}{ Gerais (22) } & Segurança Pública & 5,22727 & Desportos e Lazer & 5,50000 & 5,23182 \\
\hline & Saúde & 4,68182 & Cultura & 5,54545 & \\
\hline & Educação & 4,54545 & Administração & 5,27273 & \\
\hline & Legislativa & 4,05263 & Saneamento & 6,00000 & \\
\hline \multirow{4}{*}{$\begin{array}{l}\text { 2. São Paulo } \\
\text { (19) }\end{array}$} & Judiciária & 4,68421 & Gestão Ambiental & 4,57895 & 4,65263 \\
\hline & Segurança Pública & 4,15789 & Desportos e Lazer & 4,94737 & \\
\hline & Saúde & 4,47368 & Cultura & 4,84211 & \\
\hline & Educação & 4,36842 & Administração & 4,42105 & \\
\hline \multirow{5}{*}{$\begin{array}{l}\text { 3. Mato } \\
\text { Grosso do Sul } \\
\text { (12) }\end{array}$} & Legislativa & 4,33333 & Saneamento & 4,08333 & \\
\hline & Judiciária & 4,75000 & Gestão Ambiental & 4,50000 & 4,53333 \\
\hline & Segurança Pública & 4,75000 & Desportos e Lazer & 4,91667 & \\
\hline & Saúde & 4,00000 & Cultura & 4,75000 & \\
\hline & Educação & 4,75000 & Administração & 4,50000 & \\
\hline \multirow{5}{*}{$\begin{array}{l}\text { 4. Rio Grande } \\
\text { do Sul (61) }\end{array}$} & Legislativa & 4,27869 & Saneamento & 5,32787 & \\
\hline & Judiciária & 4,95082 & Gestão Ambiental & 4,32787 & 4,51967 \\
\hline & Segurança Pública & 3,73770 & Desportos e Lazer & 4,90164 & \\
\hline & Saúde & 3,72131 & Cultura & 5,34426 & \\
\hline & Educação & 4,04918 & Administração & 4,55738 & \\
\hline \multirow{5}{*}{$\begin{array}{l}\text { 5. Espírito } \\
\text { Santo (57) }\end{array}$} & Legislativa & 4,19298 & Saneamento & 5,56140 & \\
\hline & Judiciária & 4,96491 & Gestão Ambiental & 4,85965 & 4,51579 \\
\hline & Segurança Pública & 3,82456 & Desportos e Lazer & 5,05263 & \\
\hline & Saúde & 3,63158 & Cultura & 4,35088 & \\
\hline & Educação & 4,10526 & Administração & 4,61404 & \\
\hline \multirow{5}{*}{ 6. Acre (16) } & Legislativa & 3,81250 & Saneamento & 3,50000 & \\
\hline & Judiciária & 4,93750 & Gestão Ambiental & 4,81250 & 4,50000 \\
\hline & Segurança Pública & 4,50000 & Desportos e Lazer & 4,43750 & \\
\hline & Saúde & 4,87500 & Cultura & 4,87500 & \\
\hline & Educação & 4,93750 & Administração & 4,31250 & \\
\hline \multirow{5}{*}{$\begin{array}{l}\text { 7. Amazonas } \\
\text { (15) }\end{array}$} & Legislativa & 4,80000 & Saneamento & 3,13333 & \\
\hline & Judiciária & 4,33333 & Gestão Ambiental & 3,93333 & \\
\hline & Segurança Pública & 4,26667 & Desportos e Lazer & 4,33333 & 4,49333 \\
\hline & Saúde & 4,73333 & Cultura & 5,66667 & \\
\hline & Educação & 4,73333 & Administração & 5,00000 & \\
\hline \multirow{4}{*}{ 8. Sergipe (11) } & Legislativa & 4,18182 & Saneamento & 4,81818 & \\
\hline & Judiciária & 5,90909 & Gestão Ambiental & 4,09091 & \\
\hline & Segurança Pública & 4,54545 & Desportos e Lazer & 4,45455 & 4,48182 \\
\hline & Saúde & 3,36364 & Cultura & 4,54545 & \\
\hline
\end{tabular}




\begin{tabular}{|c|c|c|c|c|c|}
\hline & Educação & 4,54545 & Administração & 4,36364 & \multirow{6}{*}{4,32381} \\
\hline \multirow{5}{*}{ 9. Goiás (63) } & Legislativa & 3,69841 & Saneamento & 5,63492 & \\
\hline & Judiciária & 5,00000 & Gestão Ambiental & 4,82540 & \\
\hline & Segurança Pública & 3,90476 & Desportos e Lazer & 4,46032 & \\
\hline & Saúde & 3,52381 & Cultura & 4,44444 & \\
\hline & Educação & 3,50794 & Administração & 4,23810 & \\
\hline \multirow{5}{*}{$\begin{array}{l}\text { 10. Rio de } \\
\text { Janeiro (22) }\end{array}$} & Legislativa & 3,31818 & Saneamento & 4,31818 & \multirow{5}{*}{4,30000} \\
\hline & Judiciária & 4,31818 & Gestão Ambiental & 4,31818 & \\
\hline & Segurança Pública & 4,90909 & Desportos e Lazer & 4,81818 & \\
\hline & Saúde & 3,27273 & Cultura & 5,13636 & \\
\hline & Educação & 4,18182 & Administração & 4,40909 & \\
\hline \multirow{5}{*}{ 11. Bahia (31) } & Legislativa & 4,03226 & Saneamento & 4,70968 & \multirow{5}{*}{4,24194} \\
\hline & Judiciária & 3,80645 & Gestão Ambiental & 4,16129 & \\
\hline & Segurança Pública & 3,45161 & Desportos e Lazer & 4,38710 & \\
\hline & Saúde & 3,74194 & Cultura & 5,03226 & \\
\hline & Educação & 4,19355 & Administração & 4,90323 & \\
\hline \multirow{5}{*}{ 12. Piauí (10) } & Legislativa & 4,50000 & Saneamento & 3,20000 & \multirow{5}{*}{4,24000} \\
\hline & Judiciária & 4,30000 & Gestão Ambiental & 3,60000 & \\
\hline & Segurança Pública & 4,50000 & Desportos e Lazer & 3,90000 & \\
\hline & Saúde & 4,80000 & Cultura & 3,80000 & \\
\hline & Educação & 5,10000 & Administração & 4,70000 & \\
\hline \multirow{5}{*}{$\begin{array}{l}\text { 13. Distrito } \\
\text { Federal (34) }\end{array}$} & Legislativa & 3,02941 & Saneamento & 5,32353 & \multirow{5}{*}{4,21765} \\
\hline & Judiciária & 4,38235 & Gestão Ambiental & 4,73529 & \\
\hline & Segurança Pública & 4,97059 & Desportos e Lazer & 4,52941 & \\
\hline & Saúde & 2,64706 & Cultura & 5,14706 & \\
\hline & Educação & 3,73529 & Administração & 3,67647 & \\
\hline \multirow{5}{*}{$\begin{array}{l}14 . \\
\text { Pernambuco } \\
(39)\end{array}$} & Legislativa & 3,74359 & Saneamento & 3,35897 & \multirow{5}{*}{4,12564} \\
\hline & Judiciária & 4,61538 & Gestão Ambiental & 3,33333 & \\
\hline & Segurança Pública & 4,51282 & Desportos e Lazer & 4,28205 & \\
\hline & Saúde & 4,17949 & Cultura & 5,30769 & \\
\hline & Educação & 3,76923 & Administração & 4,15385 & \\
\hline \multirow[t]{5}{*}{ 15. Pará (12) } & Legislativa & 3,66667 & Saneamento & 3,08333 & \multirow{5}{*}{4,10000} \\
\hline & Judiciária & 5,00000 & Gestão Ambiental & 4,08333 & \\
\hline & Segurança Pública & 4,00000 & Desportos e Lazer & 4,66667 & \\
\hline & Saúde & 3,33333 & Cultura & 4,91667 & \\
\hline & Educação & 3,83333 & Administração & 4,41667 & \\
\hline \multirow{5}{*}{$\begin{array}{l}\text { 16. Roraima } \\
(08)\end{array}$} & Legislativa & 3,62500 & Saneamento & 3,25000 & \multirow{5}{*}{3,96250} \\
\hline & Judiciária & 4,62500 & Gestão Ambiental & 3,75000 & \\
\hline & Segurança Pública & 4,75000 & Desportos e Lazer & 4,00000 & \\
\hline & Saúde & 4,00000 & Cultura & 4,25000 & \\
\hline & Educação & 3,87500 & Administração & 3,50000 & \\
\hline \multirow{5}{*}{$\begin{array}{l}\text { 17. Amapá } \\
\text { (13) }\end{array}$} & Legislativa & 2,84615 & Saneamento & 2,38462 & \multirow{5}{*}{3,98462} \\
\hline & Judiciária & 6,23077 & Gestão Ambiental & 4,15385 & \\
\hline & Segurança Pública & 5,00000 & Desportos e Lazer & 3,69231 & \\
\hline & Saúde & 2,92308 & Cultura & 3,92308 & \\
\hline & Educação & 4,23077 & Administração & 4,46154 & \\
\hline 18. Paraná & Legislativa & 3,23077 & Saneamento & 4,92308 & \\
\hline (13) & Judiciária & 3,69231 & Gestão Ambiental & 3,92308 & \\
\hline & Segurança Pública & 3,38462 & Desportos e Lazer & 4,23077 & 3,85385 \\
\hline & Saúde & 3,76923 & Cultura & 4,53846 & \\
\hline & Educação & 3,69231 & Administração & 3,15385 & \\
\hline & Legislativa & 3,51282 & Saneamento & 4,05128 & \\
\hline & Judiciária & 4,48718 & Gestão Ambiental & 4,07692 & \\
\hline 19. Paraíba & Segurança Pública & 3,89744 & Desportos e Lazer & 3,89744 & 3,82564 \\
\hline (39) & Saúde & 3,15385 & Cultura & 4,00000 & \\
\hline & Educação & 3,23077 & Administração & 3,94872 & \\
\hline
\end{tabular}




\begin{tabular}{|c|c|c|c|c|c|}
\hline \multirow{5}{*}{ 20. Ceará (08) } & Legislativa & 4,62500 & Saneamento & 4,37500 & \multirow{5}{*}{3,76250} \\
\hline & Judiciária & 3,62500 & Gestão Ambiental & 3,37500 & \\
\hline & Segurança Pública & 2,37500 & Desportos e Lazer & 3,75000 & \\
\hline & Saúde & 3,00000 & Cultura & 4,12500 & \\
\hline & Educação & 3,87500 & Administração & 4,50000 & \\
\hline \multirow{5}{*}{$\begin{array}{l}\text { 21. Santa } \\
\text { Catarina (14) }\end{array}$} & Legislativa & 3,64286 & Saneamento & 3,21429 & \multirow{5}{*}{3,59286} \\
\hline & Judiciária & 4,64286 & Gestão Ambiental & 3,21429 & \\
\hline & Segurança Pública & 3,28571 & Desportos e Lazer & 3,85714 & \\
\hline & Saúde & 3,57143 & Cultura & 3,85714 & \\
\hline & Educação & 3,21429 & Administração & 3,42857 & \\
\hline \multirow{5}{*}{$\begin{array}{l}\text { 22. Maranhão } \\
\text { (14) }\end{array}$} & Legislativa & 3,78571 & Saneamento & 3,00000 & \multirow{5}{*}{3,58571} \\
\hline & Judiciária & 4,57143 & Gestão Ambiental & 2,92857 & \\
\hline & Segurança Pública & 3,78571 & Desportos e Lazer & 3,14286 & \\
\hline & Saúde & 3,50000 & Cultura & 3,92857 & \\
\hline & Educação & 3,28571 & Administração & 3,92857 & \\
\hline \multirow{5}{*}{$\begin{array}{l}\text { 23. Mato } \\
\text { Grosso (20) }\end{array}$} & Legislativa & 3,55000 & Saneamento & 3,30000 & \multirow{5}{*}{3,56500} \\
\hline & Judiciária & 4,20000 & Gestão Ambiental & 3,85000 & \\
\hline & Segurança Pública & 3,45000 & Desportos e Lazer & 3,50000 & \\
\hline & Saúde & 3,10000 & Cultura & 3,20000 & \\
\hline & Educação & 4,25000 & Administração & 3,25000 & \\
\hline \multirow{5}{*}{$\begin{array}{l}\text { 24. Rio } \\
\text { Grande do } \\
\text { Norte (35) }\end{array}$} & Legislativa & 3,77143 & Saneamento & 3,42857 & \multirow{5}{*}{3,43143} \\
\hline & Judiciária & 4,20000 & Gestão Ambiental & 3,57143 & \\
\hline & Segurança Pública & 3,14286 & Desportos e Lazer & 3,05714 & \\
\hline & Saúde & 2,94286 & Cultura & 3,60000 & \\
\hline & Educação & 3,11429 & Administração & 3,48571 & \\
\hline \multirow{5}{*}{$\begin{array}{l}\text { 25. Tocantins } \\
\text { (16) }\end{array}$} & Legislativa & 3,06250 & Saneamento & 3,81250 & \multirow{5}{*}{3,39375} \\
\hline & Judiciária & 4,06250 & Gestão Ambiental & 3,43750 & \\
\hline & Segurança Pública & 4,37500 & Desportos e Lazer & 3,06250 & \\
\hline & Saúde & 2,75000 & Cultura & 3,00000 & \\
\hline & Educação & 3,18750 & Administração & 3,18750 & \\
\hline \multirow{5}{*}{$\begin{array}{l}\text { 26. Rondônia } \\
\text { (23) }\end{array}$} & Legislativa & 3,82609 & Saneamento & 2,34783 & \multirow{5}{*}{3,35652} \\
\hline & Judiciária & 5,21739 & Gestão Ambiental & 2,95652 & \\
\hline & Segurança Pública & 3,69565 & Desportos e Lazer & 3,65217 & \\
\hline & Saúde & 2,73913 & Cultura & 2,78261 & \\
\hline & Educação & 3,04348 & Administração & 3,30435 & \\
\hline \multirow{5}{*}{$\begin{array}{l}\text { 27. Alagoas } \\
16)\end{array}$} & Legislativa & 3,50000 & Saneamento & 2,56250 & \multirow{5}{*}{3,23125} \\
\hline & Judiciária & 4,25000 & Gestão Ambiental & 3,25000 & \\
\hline & Segurança Pública & 2,62500 & Desportos e Lazer & 3,43750 & \\
\hline & Saúde & 2,62500 & Cultura & 3,75000 & \\
\hline & Educação & 2,50000 & Administração & 3,81250 & \\
\hline
\end{tabular}

Fonte: dados da pesquisa.

Observa-se na Tabela 1, as médias aritméticas das notas atribuídas pelos contribuintes/usuários nas 10 funções de governo escolhidas; a média geral (ranking), bem como a quantidade de contribuintes/usuários que realizaram as avaliações (após o nome de cada Estado/Distrito Federal). Não houve relevância (discrepância significativa) nos resultados das avaliações decorrentes da quantidade de avaliadores.

As notas atribuídas pelos contribuintes/usuários representam juízo de valor como forma de avaliar os resultados dos governos. De acordo com Cotta (2001), tal procedimento ocorre nas avaliações de pesquisa social aplicada. 
O Estado de Minas Gerais foi o único que obteve média geral superior a 5 (máximo de 10 pontos) nas avaliações realizadas pelos contribuintes/usuários e a função de maior média avaliada neste Estado foi a função saneamento $(6,22727)$.

A função legislativa (exercida pelas Assembleias Legislativas e Distrital) obteve a menor média no Estado do Amapá $(2,84615)$, seguido do Distrito Federal $(3,02941)$; Tocantins $(3,06250)$; Paraná $(3,23077)$; Rio de Janeiro $(3,31818)$; Alagoas (3,50000); Paraíba (3,51282); Mato Grosso (3,55000); Roraima (3,62500); Santa Catarina $(3,64286)$; Goiás $(3,69841)$; Pará $(3,66667)$; Pernambuco $(3,74359)$; Rio Grande do Norte (3,77143); Maranhão (3,78571); Acre (3,81250); Rondônia (3,82609); Bahia $(4,03226) ;$ São Paulo (4,05263); Sergipe (4,18182); Espírito Santo (4,19298); Rio Grande do Sul (4,27869); Mato Grosso do Sul (4,33333); Piauí (4,50000); Ceará $(4,62500)$; Amazonas $(4,80000)$ e Minas Gerais $(4,81818)$. Tal situação evidencia uma preocupação com o desempenho do poder legislativo (os Deputados Estaduais/Distrital foram avaliados com notas médias inferiores a 5, chegando até a 2,84615).

Destacam na Tabela 1, as maiores médias aritméticas por funções: 1) legislativa: 4,81818 - Minas Gerais; 2) Judiciária: 6,23077 - Amapá; 3) Segurança Pública: 5,22727 - Minas Gerais; 4) Saúde: 4,87500 - Acre; 5) Educação: 5,10000 Piauí; 6) Saneamento: 6,22727 - Minas Gerais; 7) Gestão Ambiental: 5,22727 - Minas Gerais; 8) Desportos e Lazer: 5,50000 - Minas Gerais; 9) Cultura: 5,66667 - Amazonas e 10) Administração: 5,27273 - Minas Gerais.

Com médias inferiores a 3 (três), os seguintes Estados foram avaliados pelos contribuintes/usuários: 1) Estado de Alagoas: Saneamento (2,56250); Educação $(2,50000)$; Segurança Pública $(2,62500)$ e Saúde $(2,625000) ; 2)$ Rondônia: Saneamento (2,34783); Saúde (2,73913); Gestão Ambiental $(2,95652)$ e Cultura $(2,78261) ; 3)$ Tocantins: Saúde (2,75000); 4) Rio Grande do Norte: Saúde (2,94286); 5) Maranhão: Gestão Ambiental (2,92857); 6) Ceará: Segurança Pública (2,37500); 7) Amapá: Saneamento $(2,38462)$ e Saúde $(2,92308) ; 8)$ Distrito Federal: Saúde $(2,64706)$. Assim pode-se observar que a função Saúde teve nota inferior a 3 em 6 Estados.

Höfling (2001) argumenta que os fatores envolvidos nas avaliações são complexos, variados e exigem grande esforço de análise. Para diminuir tal complexidade, foi realizada uma escala para ser utilizada na avaliação. As notas variaram de 1 a 10. Desse modo, pode-se afirmar que os resultados das avaliações evidenciam preocupação e descontentamento dos contribuintes/usuários pelos serviços prestados pelos governos estaduais e distrital.

O resultado da avaliação pode melhorar a qualidade do gasto público (avaliação de 10 das 28 funções atribuídas) e servir de controle social sobre a efetividade da ação do Estado nestas funções (RAMOS; SCHABBACH, 2012). 
Tabela 2 - Avaliações das funções em conjunto dos 643 contribuintes/usuários

\begin{tabular}{lccc}
\hline \multicolumn{1}{c}{ Função } & Notas & Contribuintes/usuários & Percentagem \\
\hline Legislativa & 5 & 137 & $21 \%$ \\
Judiciária & 5 & 127 & $20 \%$ \\
Segurança Pública & 3 & 117 & $18 \%$ \\
Saúde & 3 & 125 & $20 \%$ \\
Educação & 4 & 115 & $18 \%$ \\
Saneamento & 5 & 115 & $18 \%$ \\
Gestão Ambiental & 5 & 126 & $20 \%$ \\
Desportos e Lazer & 5 & 124 & $19 \%$ \\
Cultura & 5 & 111 & $17 \%$ \\
Administração & 5 & 119 & $18 \%$ \\
\hline
\end{tabular}

Fonte: dados da pesquisa.

Observa-se na Tabela 2, a concentração da nota 5 em 7 funções de governo que foram avaliadas pelos contribuintes/usuários de forma conjunta. Tal procedimento, revela preocupação com a opinião dos contribuintes/usuários: desconhecem as ações governamentais ou não querem se comprometer com a avaliação? Hipóteses que podem ser levantadas para outras pesquisas de campo, bem como outras adjacentes ao problema da pesquisa.

Na Tabela 2 sintetiza-se apenas as avaliações realizadas pelo maior número de contribuintes. Os demais avaliadores que participaram da pesquisa, como por exemplo na função legislativa (526, diferença entre 643 e 137), atribuíram a nota 1 por 86 contribuintes/usuários (13\%); nota 2 por $74(11 \%)$; nota 3 por $129(20 \%)$; nota 4 por $105(16 \%)$; nota 6 por 59 (9\%); nota 7 por $43(7 \%)$ e a nota 8 por $11(2 \%)$.

As funções Segurança Pública e Saúde também receberam a nota 3 por uma percentagem grande de contribuintes/usuários.

Seguindo as instruções de Cohen e Franco (2012), as avaliações das 10 funções de governo são classificadas nos tipos: avaliação ex-post (realizada após os seus impactos) e avaliação externa (em função de quem realiza).

Na Tabela 3 são expostos os resultados dos escores de avaliação da eficiência instrumental da política orçamentária do ano de 2012.

Tabela 3 - Resultados dos escores de avaliação da eficiência instrumental da política orçamentária dos Estados Brasileiros e a Capital Federal do ano de 2012

\begin{tabular}{lcc}
\hline DMU & Eficiência & Ranking \\
\hline ALAGOAS, AMAZONAS, BAHIA, CEARÁ, MARANHÃO, & & \\
PARAÍBA, PIAUÍ & 1 & $1^{\text {o }}$ \\
RIO GRANDE DO NORTE & 0,964918 & $2^{\underline{o}}$ \\
PARÁ & 0,956673 & $3^{\underline{0}}$ \\
PERNAMBUCO & 0,865379 & $4^{\mathbf{o}}$
\end{tabular}




\begin{tabular}{|c|c|c|}
\hline PARANÁ & 0,862871 & $5^{\mathrm{o}}$ \\
\hline GOIÁS & 0,804862 & $6^{\mathrm{o}}$ \\
\hline MATO GROSSO & 0,687877 & $7^{\mathrm{o}}$ \\
\hline SERGIPE & 0,663983 & $8^{\circ}$ \\
\hline SANTA CATARINA & 0,630227 & $9^{\mathrm{o}}$ \\
\hline RONDÔNIA & 0,623939 & $10^{\mathrm{o}}$ \\
\hline TOCANTINS & 0,610215 & $11^{\mathrm{o}}$ \\
\hline ESPÍRITO SANTO & 0,531355 & $12^{\mathrm{o}}$ \\
\hline DISTRITO FEDERAL & 0,520047 & $13^{\mathrm{o}}$ \\
\hline RIO DE JANEIRO & 0,508097 & $14^{\mathrm{o}}$ \\
\hline MINAS GERAIS & 0,496077 & $15^{\mathrm{o}}$ \\
\hline SÃO PAULO & 0,485653 & $16^{\mathrm{o}}$ \\
\hline RORAIMA & 0,481571 & $17^{\mathrm{o}}$ \\
\hline AMAPÁ & 0,444822 & $18^{\mathrm{o}}$ \\
\hline MATO GROSSO DO SUL & 0,433006 & $19^{\circ}$ \\
\hline RIO GRANDE DO SUL & 0,406953 & $20^{\circ}$ \\
\hline ACRE & 0,340614 & $21^{\circ}$ \\
\hline
\end{tabular}

Fonte: dados da pesquisa.

Os Estados de Alagoas, Amazonas, Bahia, Ceará e Maranhão, respectivamente, na $27^{\underline{a}}, 7^{\underline{a}}, 11^{\underline{a}}, 20^{\underline{a}}$ e $22^{\underline{a}}$ posição no ranking da avaliação pelos contribuintes/usuários (Tabela 1) foram avaliados como eficientes pelos dados inclusos no modelo da Tabela $3(1=100 \%)$. Isso significa que administraram de forma eficiente os recursos orçamentários do ano de 2012 na análise comparativa realizada pela Análise Envoltória de Dados com todos os Estados e o Distrito Federal.

Os demais Estados e o Distrito Federal apresentaram-se como ineficientes na execução da política orçamentária analisada. Para serem considerados eficientes, tendo como referência (benchmark) os Estados que obtiveram o escore 1 (100\%), os mesmos deveriam ter distribuído mais recursos nas funções avaliadas em relação ao total da despesa total executada (Orçamento executado de 2012).

Os Estados eficientes podem ser considerados pelo critério da avaliação de impacto (efetividade objetiva) como aqueles Estados em que houveram mudança quantitativa entre o antes e o depois da execução das funções, conforme afirmações de Figueiredo e Figueiredo (1986).

Destacam na Tabela 3, a situação dos Estados de Minas Gerais e São Paulo, considerados mais industriais que apresentaram escores inferiores a 50\% de eficiência na execução orçamentária no ano de 2012 e ainda 7 Estados (a partir de Minas Gerais) ficaram com escores inferiores a $50 \%$.

Comparando os resultados da Tabela 1 com os resultados da Tabela 3, observa-se que o Estado de Minas Gerais obteve o $1^{\circ}$ lugar $(5,23182)$ na média das notas atribuídas pelos contribuintes/usuários e o $15^{\circ}$ lugar na eficiência do ranking da execução orçamentária $(0,496077)$. Isto significa que tanto na visão dos 
contribuintes/usuários quanto da execução orçamentária comparada, o Estado de Minas Gerais pode melhorar o seu desempenho.

O Estado do Acre em $6^{\circ}$ lugar pelos contribuintes/usuários ficou em último lugar na eficiência instrumental orçamentária (34,06\%). O que também representa uma avaliação que pode ser melhorada.

As avaliações realizadas com a Análise Envoltória de Dados podem ser consideradas como avaliação de eficiência instrumental, haja vista que os inputs e outputs escolhidos apresentam relações estritas entre custos econômicos e benefícios, consoante o que argumentam Figueiredo e Figueiredo (1986).

\section{CONSIDERAÇÕES FINAIS}

Esta investigação, em atenção ao objetivo formulado, expressou a avaliação de contribuintes/usuários de 10 das 28 funções de governo que foram exercidas pelos 26 Estados Brasileiros e o Distrito Federal e divulgadas nos portais de transparência. A pesquisa divulgou também, uma correlação entre estes resultados e a avaliação de eficiência instrumental orçamentária do ano de 2012, realizada como o modelo matemático - Análise Envoltória de Dados (DEA).

De acordo com Echegaray (2001), desde seu surgimento como ferramenta fundamental de conhecimento, o papel das pesquisas de opinião pública tem sido tanto elogiado como demonizado com relação ao seus efeitos sobre o progresso e governo democráticos.

O lado positivo das pesquisas, segundo o referido autor, revelam suas contribuições para aproximar os interesses e opiniões de representados e representantes e o seu estímulo para um tipo de fiscalização pública da conduta e decisões políticas das lideranças e o lado negativo, as pesquisas são vistas como distorcendo o espírito de representação das instituições democráticas ao tornar trivial o papel das eleições e promover uma liderança irresponsiva.

Considerando o lado positivo das pesquisas de opinião pública, espera-se que o resultado dessa investigação possa motivar mais pesquisas sociais de avaliação de políticas governamentais, haja vista que consoante o disposto na Lei de Responsabilidade Fiscal (BRASIL, 2000), os cidadãos têm o direito de exercer o controle social, quer tomando ciência da divulgação dos resultados expressos nos portais de transparência, bem como se manifestando sobre os mesmos.

Convém ressalvar, que o modelo DEA contribui para avaliar a eficiência instrumental no setor público. Ao definir outras variáveis, mudam-se os resultados, mas o modelo indica conclusões importantes que deveriam ter sido feitas para se tornarem eficientes. A variedade de insumos e produtos (variáveis) que pode ser utilizada no modelo DEA não representa limitações no modelo e sim formas alternativas de avaliar, desde que tais variáveis sejam devidamente justificadas.

A satisfação dos contribuintes sobre os serviços decorrentes das diversas funções de governo (saúde, educação, segurança pública, transporte etc.) é uma 
medida de aferição de resultado relevante, haja vista que além de financiar as ações governamentais (com impostos, taxas, contribuições etc.), os mesmos são os beneficiários/usuários e têm o direito de exigir que os governantes sejam eficientes. Suas opiniões podem mudar as políticas públicas.

Embora, os resultados da pesquisa representam avaliações relevantes, os mesmos estão sujeitos a limitações: não houve espaço no questionário para o respondente fazer considerações sobre a sua avaliação e não houve exigência de idade para participar da pesquisa.

Recomenda-se mais pesquisas de avaliação de funções de governo, tanto no sentido de incluir as limitações da pesquisa, bem como testar outras formas de obter as avaliações. Os agentes públicos, o controle interno, externo e social serão beneficiados.

Conclui-se que o Estado de Minas Gerais, seguido de São Paulo e Mato Grosso do Sul foram os melhores avaliados pelos contribuintes/usuários e Tocantins, Rondônia e Alagoas obtiveram as menores médias nas avaliações das 10 funções de governo. As funções segurança pública e saúde foram avaliadas de forma conjunta com a nota final 3 (18\% e 20\%, respectivamente dos 643 contribuintes/usuários participantes da pesquisa) e educação com a nota 4 (18\%). Em relação a eficiência instrumental orçamentária de 2012, os Estados de Alagoas, Amazonas, Bahia, Ceará e Maranhão foram considerados eficientes, mas em relação à percepção dos contribuintes/usuários, os mesmos ficaram na $27^{\underline{a}}, 7^{7 \underline{a}}, 11^{\underline{a}}, 20^{\underline{a}}$ e $22^{\underline{a}}$ posição no ranking da avaliação.

\section{REFERÊNCIAS}

ALA-HARJA, Marjukka; HELGASON, Sigurdur. Em direção às melhores práticas de avaliação. Revista do Serviço Público, Ano 51, Número 4, Out-Dez 2000.

BRASIL. Constituição da República Federativa do Brasil de 1988. Diário Oficial [da] República Federativa do Brasil, no 191-A, de 05 out. 1988.

BRASIL. Lei Complementar n 101, de 04 de maio de 2000 (Lei de Responsabilidade Fiscal - LRF). Estabelece normas de finanças públicas voltadas para a responsabilidade na gestão fiscal e dá outras providências. Diário Oficial [da] República Federativa do Brasil, Brasília, 05 de maio de 2000.

BRASIL. Lei no 11.653, de 7 abril de 2008. Dispõe sobre o Plano Plurianual para o período 2008/2011. Diário Oficial [da] República Federativa do Brasil, Brasília, DF, 8 de abril de 2008.

BRASIL. Ministério do Planejamento, Orçamento e Gestão (MPOG). Portaria no 42, de 14 de abril de 1999. Atualiza a discriminação da despesa por funções de que 
tratam o inciso I do $\S 1^{\circ}$ do art. $2^{\circ}$ e $\S 2^{o}$ do art. $8^{\circ}$, ambos da Lei $n^{\circ} 4.320$, de 17 de março de 1964, estabelece os conceitos de função, subfunção, programa, projeto, atividade, operações especiais, e dá outras providências. Diário Oficial [da] República Federativa do Brasil, Brasília, DF, 15 de abril de 1999.

BRASIL. Ministério da Fazenda. Secretaria do Tesouro Nacional (STN). Prefeituras e Governos Estaduais - Execução Orçamentária de Estados (1995-2012). Disponível em: <https://www.tesouro.fazenda.gov.br/pt/prefeituras-governos-estaduais/sobre>. Acesso em: 12 jul. 2013.

CAIDEN; Gerald; CAIDEN, Naomi. Enfoques y lineamientos para el seguimiento, la medición y la evaluación del desempeño en programas del sector público. Revista do Serviço Público. Ano 52, Número 1, Jan-Mar 2001.

COHEN, Ernesto; FRANCO, Rolando. Avaliação de projetos sociais. 10. ed. Petrópolis: Vozes, 2012.

COSTA, Frederico Lustosa da; CASTANHAR, José Cezar. Avaliação de programas públicos: desafios conceituais e metodológicos. RAP, Rio de Janeiro 37 (5): 969-92, Set./Out. 2003.

COTTA, Tereza Cristina. Avaliação educacional e políticas públicas: a experiência do Sistema Nacional de Avaliação da Educação Básica (SAEB). Revista do Serviço Público, Ano 52, Número 4, Out-Dez 2001.

DRAIBE, Sônia Miriam. Avaliação de implementação: esboço de uma metodologia de trabalho em políticas públicas. In: BARREIRA, Maria Cecília Roxo Nobre; CARVALHO; Maria do Carmo Brant de (Org.). Tendências e perspectivas na avaliação de políticas e programas sociais. São Paulo: IEE/PUC-SP, 2001.

ECHEGARAY, Fabián. O papel das pesquisas de opinião pública na consolidação da democracia: a experiência latino-americana. Opinião Pública, Campinas, Vol. VII, nำ1, 2001, pp.60-74.

FARIA, Flávia Peixoto; JANNUZZI, Paulo de Martino; SILVA, Silvano José da. Eficiência dos gastos municipais em saúde e educação: uma investigação através da análise envoltória no estado do Rio de Janeiro. RAP - Rio de Janeiro 42(1):155-177, Jan./Fev. 2008.

FERREIRA, Carlos Maurício de Carvalho; GOMES, Adriano Provezano. Introdução à análise envoltória de dados: teoria, modelos e aplicações. Viçosa: Editora UFV, 2009. 
FIGUEIREDO, Marcus Faria; FIGUEIREDO, Argelina Maria Cheibub. Avaliação política e avaliação de políticas: um quadro de referência teórica. Análise \& Conjuntura., Belo Horizonte, 1 (3): 107 - 127, set./dez. 1986.

GIACOMONI, James. Orçamento público. 9. Ed. São Paulo: Atlas, 2000.

HÖFLING, Eloisa de Mattos. Estado e políticas (públicas) sociais. Cadernos Cedes, ano XXI, no 55, novembro/2001.

KOHAMA, Hélio. Contabilidade pública: teoria e prática. 10. ed. São Paulo: Atlas, 2009.

MEZA, Lidia Angulo; NETO, Luiz Biondi; MELLO, João Carlos Correia Baptista Soares de; GOMES, Eliane Gonçalves. SIADv3.0 - Sistema Integrado de Apoio à Decisão: uma implementação computacional de modelos de análise de envoltória de dados. Disponível em: <http://www.uff.br/decisao. Acesso em 08 jul. 2011.

MODESTO, Paulo. Notas para um debate sobre o princípio da eficiência. Revista do Serviço Público, Ano 51, Número 2, Abr-Jun 2000.

PEDROSO, Marcel de Moraes; CALMO, Paulo Carlos Du Pin; BANDEIRA, Ludmila Ferreira. O uso da análise envoltória de dados para avaliação da gestão do Programa Bolsa-Família. Com. Ciências Saúde. 2009; 20 (1): 37-44.

RAMOS, Marília Patta; SCHABBACH, Letícia Maria. O estado da arte da avaliação de políticas públicas: conceituação e exemplos de avaliação no Brasil. Rev. Adm. Pública - Rio de Janeiro 46(5): 1271-294, set./out. 2012.

SATO, James Magalhães. Utilização da Análise Envoltória de Dados (DEA) no estudo de eficiência do setor de saneamento. 43 f. Dissertação (Mestrado em Economia Regional). Universidade Católica de Brasília, 2011.

SILVA, Lino Martins da. Contabilidade governamental: um enfoque administrativo da nova contabilidade pública. 8. ed. São Paulo: Atlas, 2009.

SOUZA, Celina. Políticas públicas: um revisão da literatura. Sociologias. Porto Alegre, ano 8, nº 16, jul/dez 2006, p. 20-45. 